\title{
A Case of Recurrent Tumoral Calcinosis in a Young Female
}

\author{
Abhishek Kumar, Pawan Singh, Heena Dobhal
}

\begin{abstract}
Tumoral calcinosis, a rare benign clinical condition resembling a neoplasm is characterized by calcium and phosphate deposits, usually located around large joints. It can be primary or secondary to renal failure and hyperparathyroidism. This report describes a rare case of tumoral calcinosis in a 13 years old girl presenting as a huge lump around left shoulder and elbow joint with discharging sinus over left infraclavicular region.
\end{abstract}

Keywords: Calcinosis, Hyperphosphatemia, GALNT3, FGF 23.

How to cite this article: Kumar A, Singh P, Dobhal H. A Case of Recurrent Tumoral Calcinosis in a Young Female. World J Endoc Surg 2013;5(1):18-20.

\section{Source of support: Nil}

\section{Conflict of interest: None}

\section{INTRODUCTION}

Tumoral calcinosis is a rare condition characterized by hyperphosphatemia, normocalcemia and deposits of calcium phosphate, usually adjacent to large joints such as the extensor aspect, hip and elbow. ${ }^{1}$ It manifests in childhood or adolescence as painless, firm, mobile tumor-like masses in the soft tissue around the joint that may interfere with joint function when large. Its natural history is not well understood. Inborn errors of metabolism, or transport of phosphorus $^{2}$ or a genetically conditioned predisposition of collagen toward calcification have all been suggested as possible underlying mechanism. Mutations in the UDP-Nacetyl-alpha-D-galactosamine: Polypeptide N-acetylgalactosaminyltransferase-3 (GALNT3) and fibroblast growth factor-23 (FGF23) genes have been described. ${ }^{2-4}$ Mutational analysis is important for the early recognition of the disorder, for prevention of its complications and for family screening strategies. It is usually familial and recurrence after excision is frequent. ${ }^{5,6}$ We describe here a case of tumoral calcinosis in a 13 years old female.

\section{CASE REPORT}

A 13 years old female presented with gradually increasing, painless, firm masses over the left elbow (Fig. 1) and shoulder joint present for last 2 years. She had no systemic symptoms. There was no family history of trauma or administration of any medication prior to appearance of swellings. There was no history of excessive milk or antacid intake, endocrine abnormalities or any history suggestive of connective tissue disease. There was no history of similar condition in family members. On examination there was firm to hard, nontender, irregular tumorous mass over the left shoulder joint measuring $14 \times 12 \mathrm{~cm}$ in size and other over left elbow extensor surface measuring about $6 \times 8 \mathrm{~cm}$. Overlying skin of left infraclavicular region (Fig. 2) having a discharging sinus with chalky white discharge. Two scars of previous operation for the same where present over right elbow (Fig. 3) and lower back region. There was minimal restriction of movement at joints. Systemic examination results were normal. Hemogram, liver and renal function and the erythrocyte sedimentation rate were normal. Serum phosphorus was raised at $6.4 \mathrm{mg}$. Serum calcium, uric acid, alkaline phosphate, parathyroid hormone, calcitonin levels

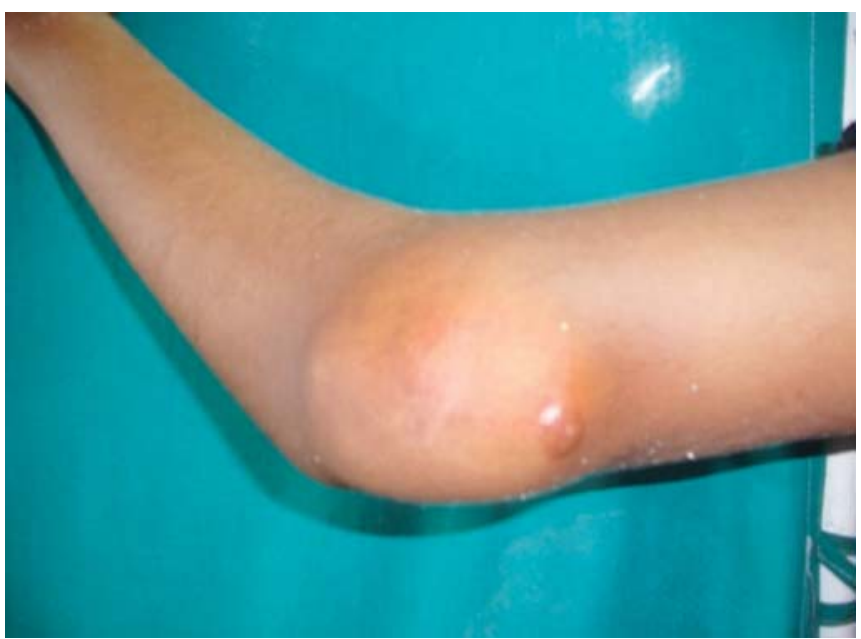

Fig. 1: Tumoral calcinosis of left elbow joint

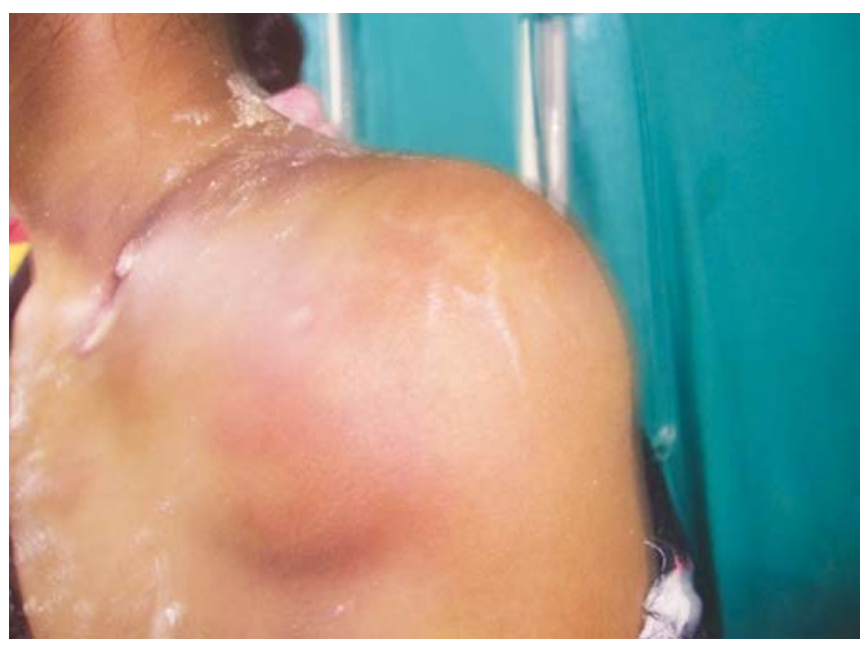

Fig. 2: Discharging sinus over left infraclavicular region 
were normal. Due to economic constraints, FGF23 analysis was not done. Radiographs (Fig. 4) showed large, lobulated, radiopaque, soft tissue masses of calcific density in juxtaarticular position. MRI (Fig. 5) of left shoulder showed calcified subcutaneous mass lesion around left shoulder joint in the region of deltoid muscle and anterior to clavicle. Multiple fluid levels are seen within the lesion. Small similar signal intensity lesion also seen in subscapularis bursa. Histopathology (Fig. 6) from the right elbow showed deeply basophilic amorphous granular material surrounded by dense fibrous tissue and infiltration. Patient was put on phosphorus binding antacid to lower the intestinal absorption of phosphorus and her diet adjusted to lower its intake. On subsequent monthly follow-up, her serum phosphorous came down to $3.1 \mathrm{mg}$. The discharging sinus in the infraclavicular region required daily dressing. The old operative scar in the right elbow region had developed another discharging sinus which required hospitalization and wound care and has recently been excised and defect covered by split-skin graft.

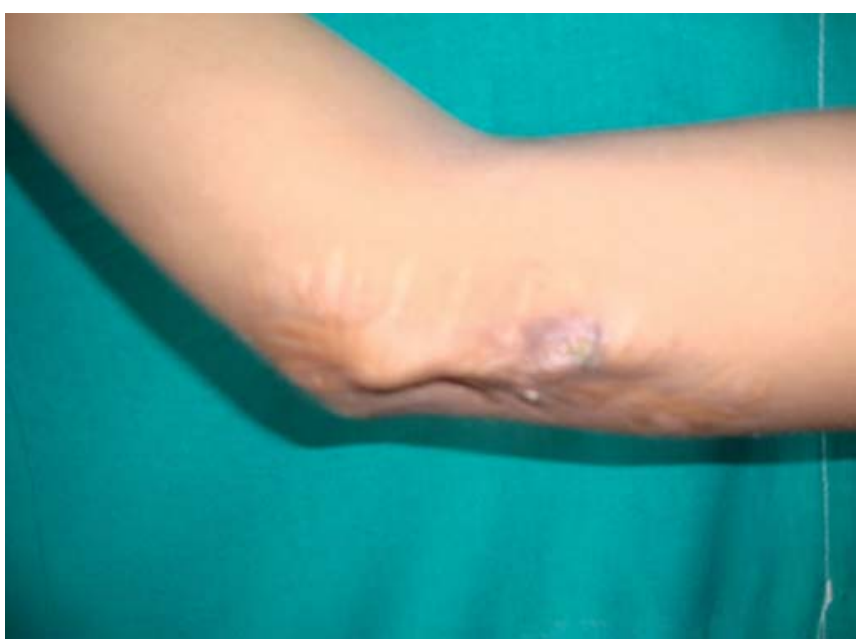

Fig. 3: Operated scar over right elbow

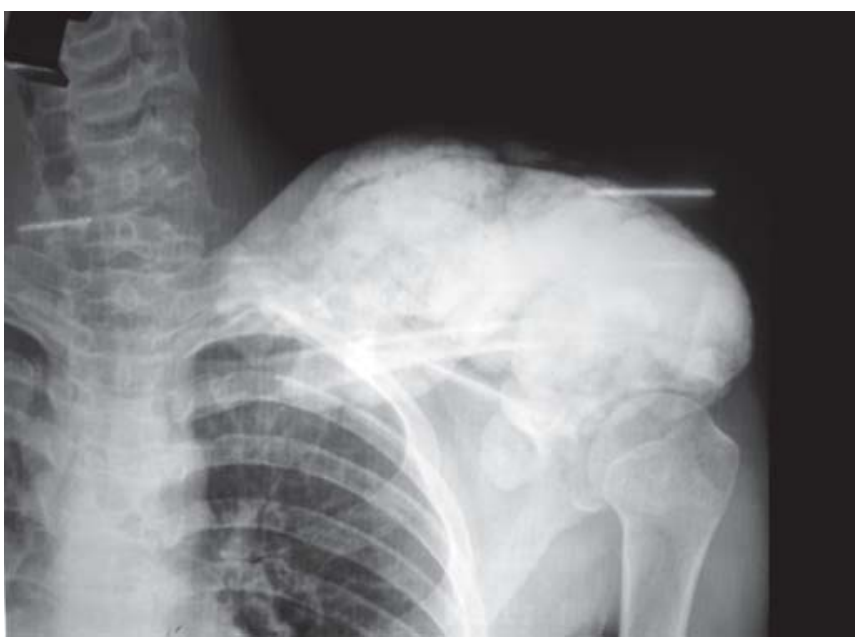

Fig. 4: X-ray chest showing calcification over left shoulder region

\section{DISCUSSION}

Tumoral calcinosis was first described in $1899 .{ }^{7}$ The pathogenesis is obscure but the basic defect is thought to be in the proximal renal tubular cell with an elevated renal phosphate reabsorption threshold and increased production of 1, 25-dihydroxyvitamin D. It is classified into three types depending upon the pathogenesis; primary normophosphatemic tumoral calcinosis (NPTC), primary hyperphosphatemic tumoral calcinosis (PHTC) and secondary tumoral calcinosis. $^{8}$ Our case is subtype 2 .

The combination of excess phosphate and normocalcemia often causes calcium and phosphate to deposit in the skin and subcutaneous tissues. Clinical findings vary among patients: Some masses are painful and swollen while others are not. Many of the masses cause erosion of the skin and extrude a white or yellow chalky substance resembling pus. While CT is best for demonstrating the extensive calcification within masses, MRI may be useful in depicting the tissue characteristics of lesion. These masses are typically hypointense on T1W and heterogeneously

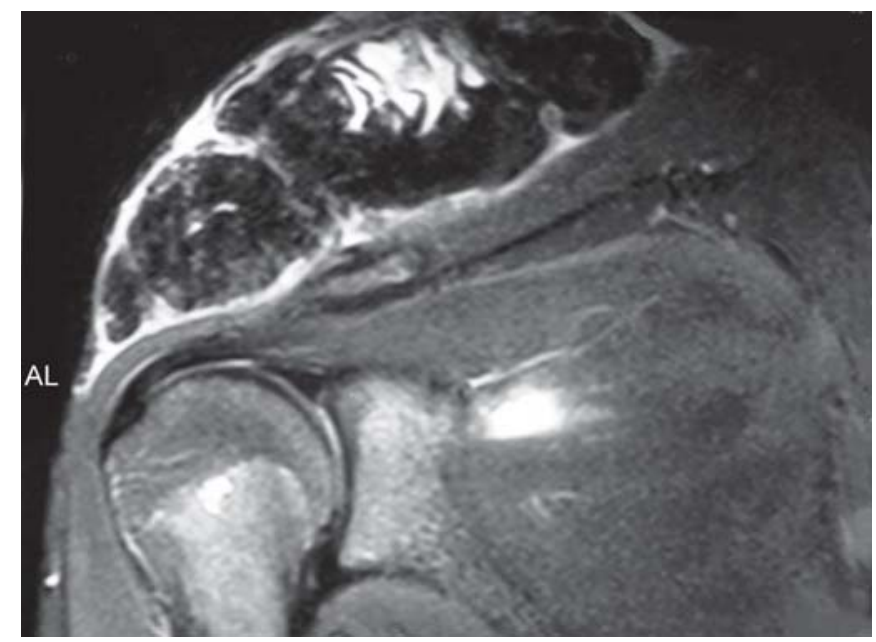

Fig. 5: MRI of left shoulder joint showing large lobulated calcified subcutaneous mass lesion superior to clavicle

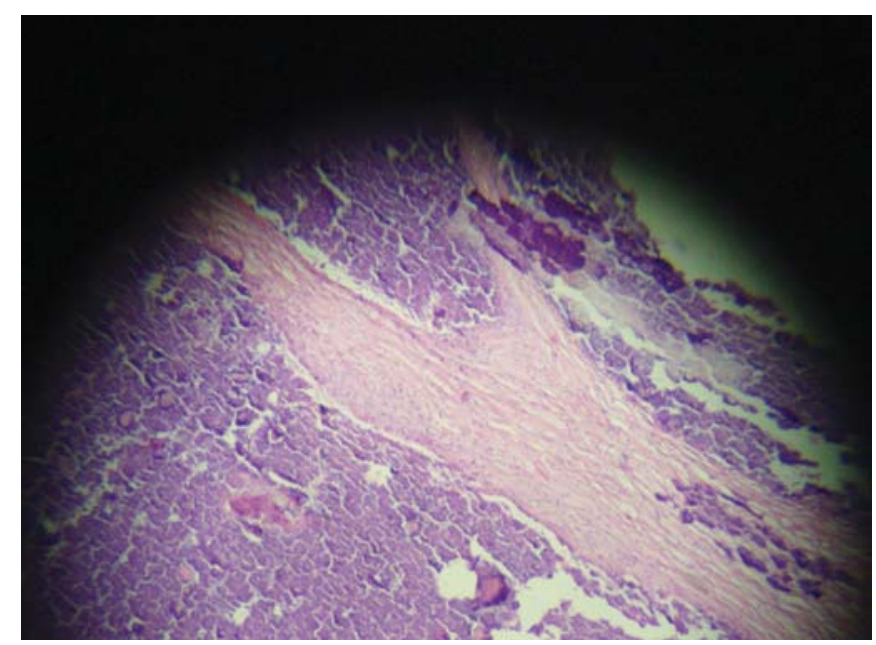

Fig. 6: Histopathological examination showing calcium deposits 
hyperintense on T2W images, sometimes with fluid-fluid levels apparent.

Tumoral calcinosis is often not considered as a potential diagnosis in very young patients, and has been depicted as difficult to diagnose even in adult patients. Despite distinctive radiological features, Steinbach et al observed that five of 12 patients were misdiagnosed prior to biopsy, and their initial diagnoses included osteosarcoma, chondrosarcoma, abscess and a herniated bowel. ${ }^{6}$

In addition to tumoral calcinosis, the differential diagnosis for a calcified soft tissue mass is lengthy and includes: Heterotopic ossification (myositis ossificans), calcified hemangioma or lymphangioma, teratoma, parosteal osteosarcoma and soft tissue sarcomas, metachondromatosis, chronic renal failure, calcinosis universalis, hypervitaminosis D, milk-alkali syndrome, and calcinosis circumscripta.

Typical clinical findings, radiology, fine needle aspiration cytology and histopathology showing calcification helps in diagnosis. Complete surgical excision has been recommended but recurrences are common. ${ }^{6,9}$

\section{REFERENCES}

1. Alkhooly AZ. Medical treatment for tumoral calcinosis with 8 years follow-up: A report of four cases. J Ortho Surg 2009;17(3):379-82.

2. Yu X, White KE. FGF23 and disorders of phosphate homeostasis. Cytokine Growth Factor Rev 2005 Apr;16(2):221-32.

3. Masi L, Gozzini A, Franchi A, Campanacci D, et al. A novel recessive mutation of fibroblast growth factor-23 in tumoral calcinosis. J Bone Joint Surg Am 2009 May;91(5):1190-98.
4. Specktor P, Cooper JG, Indelman M, Sprecher E: Hyperphosphatemic familial tumoral calcinosis caused by a mutation in GALNT3 in a European kindred. J Hum Genet 2006;51: 487-90.

5. Prahinski JR, Schaefer RA. Tumoral calcinosis of the foot. Foot Ankle Int 2001;22:911-13.

6. Steinbach LS, Johnston JO, Tepper EF, Honda GD, Martel W. Tumoral calcinosis: Radiologic-pathologic correlation. Skeletal Radiol 1995;24(8):573-78.

7. Kumaran MS, Bhadada S, Bhansali A, Shriram M, Kumar B. Young boy with multiple periarticular swellings and discharging sinuses: Tumoral calcinosis. Indian J Pediatr 2004 Dec;71(12): e74-76.

8. Lin S, Daruwalla JS. Tumoral calcinosis: A case report. Am Acad Med Singapore 1985;4:391.

9. Lyles KW, Halsey DL, Friedman NE, Lobaugh B. Correlations of serum concentration of 1,25 dihydroxyvitamin $\mathrm{D}$, phosphorus and parathyroid hormone in tumoral calcinosis. J Clin Endocrinol Metab 1988;67:88.

\section{ABOUT THE AUTHORS}

\section{Abhishek Kumar (Corresponding Author)}

Senior Resident, Department of Surgery, GSVM Medical College Kanpur, Uttar Pradesh, India, e-mail: drabhisheksurg@gmail.com

\section{Pawan Singh}

Lecturer, Department of Surgery, GSVM Medical College, Kanpur Uttar Pradesh, India

\section{Heena Dobhal}

Junior Resident, Department of Surgery, GSVM Medical College Kanpur, Uttar Pradesh, India 